\title{
Opportunistic screening for genital Chlamydia trachomatis infection and partner follow-up in family planning clinics in three Scottish cities
}

\author{
Ahilya Noone, MSc, FFPHM, Consultant Epidemiologist, Scottish Centre for Infection and Environmental Health, Glasgow, \\ UK; Aileen Spiers, BSc, RM, Research Nurse, The Sandyford Initiative, Glasgow, UK, Gwen Allardice, PhD, CStat, Lecturer, \\ Department of Statistics and Modelling Science, University of Strathclyde, Glasgow, UK, Susan Carr, MRCOG, DFFP, \\ Consultant in Family Planning and Reproductive Health, The Sandyford Initiative, Glasgow, UK; Gillian Flett, FRCOG, MFFP, \\ Consultant in Family Planning and Reproductive Health Medicine, Square 13, Golden Square, Aberdeen, UK; \\ Audrey Brown, MRCOG, DFF, Head of Family Planning and Well Woman Service, Carnegie Clinic, Dunfermline, UK; \\ Sara Twaddle*, MSc, PhD, Head of Research and Development, Stobhill Hospital, Glasgow, UK
}

*Current post: Director, Scottish Intercollegiate Guidelines Network, Royal College of Physicians, Edinburgh, UK

Correspondence: Dr Ahilya Noone, Scottish Centre for Infection and Environmental Health, Clifton House, Clifton Place Glasgow G3 7LN, UK. Tel: +44 (0) 141300 1100. E-mail: ahilya.noone@scieh.csa.scot.nhs.uk

(Accepted 11 January 2004)

Journal of Family Planning and Reproductive Health Care 2004; 30(2): 84-85

\begin{abstract}
Three large urban family planning clinics (FPCs) in Scotland participated in a study to examine the implications of opportunistically offering urine testing for genital Chlamydia trachomatis infection and FPC follow-up of positive women and of their male partners. Ninety-eight percent (3029) of women accepted the test. The prevalence of infection was $5.2 \%$ and this decreased significantly with age. There was no significant difference in prevalence between centres. Ninety-one percent of positive women intended to inform at least one partner about their infection status. Pretest counselling took about 10 minutes per woman while management (excluding full screening for sexually transmitted infections) of positive women took an additional 10 minutes. Screening in the FPC is acceptable to many women and to some of their male partners. Training and resources for administration and staffing are required if opportunistic screening is to be implemented.
\end{abstract}

\section{Key message points}

- Opportunistic testing for genital Chlamydia trachomatis infection is acceptable to the majority of women who attend family planning clinics.

- A small minority of women remains reluctant to be tested: this issue needs to be addressed.

- Additional resources are required to implement the full range of sources for opportunistic testing.

- Women who have the infection find it hard to discuss this with their male partners.

- 'Unisex' clinics where men as well as women can discuss sexual health matters should be promoted.

\section{Introduction}

The advent of nucleic acid amplification (NAA) tests for genital Chlamydia trachomatis infection, more sensitive than tests previously used and which can be used on urine samples, allows diagnosis of this often-asymptomatic infection. Opportunistic testing of women has been recommended to reduce the burden of long-term morbidity. 1,2

This study aimed to determine the prevalence of genital C. trachomatis infection in women attending urban family planning clinics (FPCs) in Scotland and the implications of opportunistically offering urine testing and follow-up in the FPC to women attending, and to their male partners if acceptable.

\section{Method}

A random sample of women attending FPCs in Glasgow, Edinburgh and Aberdeen between November 2000 and June 2001 were invited by research nurses to consent to take part in the study. At each centre the recruitment target was an unbiased sample of 250 women aged $<20,20-24$, $25-29$ and $\geq 29$ years. Sexual behaviour information was provided anonymously, a first void specimen of urine for testing was obtained and an anonymous study proforma completed. Women received their usual clinical care in the clinic. If an endocervical swab was taken in the course of routine clinical care (screening or symptomatology) a firstvoid urine was not obtained.

Laboratory testing was performed using the $\mathrm{LCx}$ probe system (Abbot Diagnostics Maidenhead, UK) (Glasgow and Edinburgh FPCs) and the Probetec Chlamydia trachomatis amplified DNA assay (Becton Dickinson, Oxford, UK) (Aberdeen FPC) according to the manufacturers' instructions.

As is normal clinical practice, women were informed of the test result. Up to three reminders were sent to those with positive tests to tell them of the need for further advice, treatment and partner follow-up, the latter being available at the FPC if requested. Women with positive tests and attending partners were counselled and treated with azithromycin $1 \mathrm{~g}$ stat. Partners were also offered a urine test. The women provided information about treatment of other partners elsewhere.

All variables collected were examined as potential risk factors for infection by univariate logistic regression. Those factors found significant were then examined in a multivariate logistic regression. Analyses were performed using the Statistical Products and Software Solutions (SPSS, Chicago, IL, USA).

Ethical committees' approval was obtained for the study.

\section{Results}

Ninety-eight percent (3029/3094) of women accepted the test. Refusal rates were similar and low in all age groups. Reasons given for refusal included: self-perception of low risk because of steady relationship or no current partner, recent/previous chlamydia test, unwilling to give urine specimen at this appointment, and upset because of positive pregnancy test. 
Table 1 Risk factors for genital chlamydia infection: results of multivariate logistic regression analysi

\begin{tabular}{|c|c|c|c|c|c|}
\hline \multirow[t]{2}{*}{ Variable } & \multicolumn{2}{|c|}{ Positive? } & \multirow[b]{2}{*}{$\mathrm{n}$} & \multirow{2}{*}{$\begin{array}{l}\text { Prevalence } \\
(\%)\end{array}$} & \multirow[t]{2}{*}{$\mathrm{p}^{\mathrm{a}}$} \\
\hline & No & Yes & & & \\
\hline \multicolumn{6}{|l|}{ Centre } \\
\hline Glasgow & 988 & 61 & 1049 & 5.8 & \multirow[t]{3}{*}{0.43} \\
\hline Edinburgh & 957 & 54 & 1011 & 5.3 & \\
\hline Aberdeen & 925 & 44 & 969 & 4.5 & \\
\hline \multicolumn{6}{|l|}{ Age group (years) } \\
\hline$<20$ & 659 & 71 & 730 & 9.7 & \multirow[t]{4}{*}{$<0.0001$} \\
\hline $20-24$ & 777 & 58 & 835 & 6.9 & \\
\hline $25-29$ & 716 & 19 & 735 & 2.6 & \\
\hline$\geq 29$ & 718 & 11 & 729 & 1.5 & \\
\hline \multicolumn{6}{|l|}{ Marital status } \\
\hline Married (ongoing) & 346 & 6 & 352 & 1.7 & \multirow[t]{5}{*}{0.004} \\
\hline Cohabiting & 752 & 32 & 784 & 4.1 & \\
\hline $\begin{array}{l}\text { Married and } \\
\text { separated }\end{array}$ & 67 & 4 & 71 & 5.6 & \\
\hline Widowed/divorced & 64 & 3 & 67 & 4.5 & \\
\hline Single & 1368 & 94 & 1462 & 6.4 & \\
\hline \multicolumn{6}{|l|}{ Current contraception } \\
\hline None & 220 & 10 & 230 & 4.3 & \multirow[t]{4}{*}{0.9} \\
\hline Condom & 1568 & 89 & 1657 & 5.4 & \\
\hline Pill & 1509 & 82 & 1591 & 5.2 & \\
\hline Other & 522 & 28 & 550 & 5.1 & \\
\hline \multicolumn{6}{|l|}{$\begin{array}{l}\text { Antibiotic use } \\
\text { (previous } 4 \text { weeks) }\end{array}$} \\
\hline Yes & 149 & 8 & 157 & 5.1 & \multirow[t]{2}{*}{0.56} \\
\hline No & 2722 & 151 & 2872 & 5.3 & \\
\hline \multicolumn{6}{|l|}{ 'Ever treated for STI' } \\
\hline Yes & 334 & 14 & 348 & 4.0 & \multirow[t]{2}{*}{0.29} \\
\hline No/Not known & 2369 & 134 & 2369 & 5.7 & \\
\hline \multicolumn{6}{|c|}{ 'Ever been to GUM/STD' } \\
\hline Yes & 331 & 12 & 343 & 3.5 & \multirow[t]{2}{*}{0.13} \\
\hline No/Not known & 2377 & 136 & 2513 & 5.4 & \\
\hline \multicolumn{6}{|l|}{ Current steady partner } \\
\hline Yes & 2285 & 119 & 2404 & 5.0 & \multirow[t]{2}{*}{0.15} \\
\hline No/Not known & 585 & 40 & 625 & 6.4 & \\
\hline $\begin{array}{l}\text { Use condom with ste } \\
\text { partner }\end{array}$ & & & & & \\
\hline Never & 781 & 41 & 822 & 5.0 & 0.49 \\
\hline Always & 452 & 19 & 471 & 4.0 & \\
\hline Sometimes & 1041 & 60 & 1101 & 5.4 & \\
\hline $\begin{array}{l}\text { Number of partners i } \\
\text { last year }\end{array}$ & & & & & \\
\hline None & 1168 & 46 & 1214 & 3.8 & $<0.0001$ \\
\hline $1-2$ & 243 & 55 & 298 & 18.5 & \\
\hline $3+$ & 199 & 28 & 227 & 12.3 & \\
\hline Reason for attending & & & & & \\
\hline Contraception & 1497 & 63 & 1560 & 4.0 & 0.022 \\
\hline $\begin{array}{l}\text { Emergency } \\
\text { contraception }\end{array}$ & 331 & 22 & 353 & 6.2 & \\
\hline Other & 516 & 36 & 552 & 6.5 & \\
\hline Pregnancy & 526 & 38 & 564 & 6.7 & \\
\hline $\begin{array}{l}\text { Signs/symptoms of } \mathrm{g} \\
\text { infection }\end{array}$ & & & & & \\
\hline No & 2526 & 128 & 2654 & 4.8 & 0.005 \\
\hline Yes & 344 & 31 & 375 & 8.3 & \\
\hline
\end{tabular}

aThe figures in bold indicate statistical significance.

FPC, family planning clinic; GUM, genitourinary medicine clinic; STD sexually transmitted disease clinic; STI, sexually transmitted infection.

The prevalence of infection was 5.2\% (159/3029) overall and decreased with age $(\mathrm{p}<0.0001)$ (Table 1$)$. There was no significant difference in prevalence between centres. Significant differences in prevalence of infection $(\mathrm{p}<0.05)$ were also found by marital status, number of partners in last year, reason for attending the FPC, and signs/symptoms of genital infection.

Ninety-one percent $(145 / 159)$ of positive women returned to the clinic for care. Of these, $91 \%(132 / 145)$ were intending to inform at least one partner of their infection status; women were less willing to inform previous partners. Only 57\% (83/145) of women were screened for sexually transmitted infections (STIs) in the clinic and no woman was found to have an STI.

Eighty 'first-mentioned' partners of the 159 positive women $(50 \%)$ were reported to have been treated for genital chlamydia infection. A total of 33 partners attended the FPC, 24 accepted a urine test and 14 tested positive.

The research nurses reported that pretest counselling and screening of the women took 10 minutes per woman on average and that counselling and management of a positive woman took 10 minutes. The latter estimate does not include time for STI screening of positive women or partner counselling and treatment.

\section{Discussion}

The very high acceptance rate demonstrates the acceptability of opportunistic testing in the FPC setting. The overall prevalence of $5.2 \%$ is comparable with recently published Scottish data based on NNA tests. 3,4

The reasons given by women for refusing the offer of a test and their unwillingness to inform all partners demonstrated that much work remains to be done to inform women and men about genital chlamydia and to help them act to protect themselves from the infection and its sequelae. There is also strong support for the argument that men should be screened, 5 especially in view of women's reluctance to inform previous partners of their infection and the high proportion of male partners who were tested at the FPC and found to be positive.

FPC staff members already have skills in sexual behaviour counselling and in gynaecology. It is also encouraging that some male partners are willing to be treated in these clinics. The notion of 'unisex' care is an attractive one with the added benefit of shared sexual health responsibility.

Opportunistic screening in the FPC for genital $C$. trachomatis infection in women and their partners can be feasible and effective only if there are additional resources for staff training and for counselling, for treatments, and for screening for and management of STI. The advent of integrated family planning and genitourinary medicine services will facilitate opportunistic testing of females and males within the same health care location.

Statements on funding and competing interests

Funding. This study was funded by the Chief Scientist Office, Scottish Executive Health Department, Edinburgh, UK.

Competing interests. None identified.

\section{Acknowledgements}

The authors thank the women who took part in the study. They also acknowledge the contributions of the clinic research nurses, Clair Smith, Anne Ratray and Zofia Zyborska, of Claire Williams and Ian Primrose who undertook data entry, and of Dr Hamish McKenzie (Aberdeen) and Dr Hugh Young (Edinburgh) in whose laboratories microbiological testing was performed. Sadly, Robert McCartney, Head Biomedical Scientist, Regional Virus Laboratory, Gartnavel Hospital, Glasgow, UK, who was one of the main investigators, died during the course of the study.

References

1 Chief Medical Officer's (CMO) Expert Advisory Group. Chlamydia trachomatis: Summary and Conclusions of CMO's Expert Advisory Group. London, UK: Department of Health, 1998.

2 Scottish Intercollegiate Guidelines Network (SIGN). Management of Genital Chlamydia Infection. A National Clinical Guideline. Edinburgh, UK: SIGN, March 2000.

3 Kirkwood K, Horn K, Glasier A, et al. Non-invasive screening of teenagers for Chlamydia trachomatis in a family planning setting. $\mathrm{Br}$ J Fam Plann 1999; 24: 11-12.

4 Macmillan S, McKenzie H, Flett G, et al. Which women should be tested for Chlamydia trachomatis? Br J Obstet Gynaecol 2000; 107: 1088-1093.

5 Fenton KA. Screening for Chlamydia trachomatis: have we fully explored the possibilities? Commun Dis Public Health 2000; 3: 86-89. 